\title{
FITOSSANIDADE
}

\section{ATIVIDADE PECTINOLÍTICA DE COLLETOTRICHUM GLOEOSPORIOIDES E A RELAÇÃO COM A AGRESSIVIDADE AO STYLOSANTHES SPP. ${ }^{\left.{ }^{1}\right)}$}

\author{
CARLOS EDUARDO MARCHI $\left({ }^{2 *}\right)$; CELSO DORNELAS FERNANDES $\left({ }^{3,4}\right)$; LUCIANA ROBERTA DE ARAÚJO \\ GUIMARÃES $\left({ }^{5}\right)$; LARISSA RODRIGUES FABRIS $\left({ }^{6}\right)$; MIRIAN DE FREITAS BORGES $\left({ }^{2}\right)$; \\ RENATA ALINE TRENTIN $\left({ }^{5}\right)$; VANESSA DE FÁTIMA JERBA $\left({ }^{3}\right)$
}

\begin{abstract}
RESUMO
A produção de pectinases de 40 isolados de Colletotrichum gloeosporioides, obtidos de Stylosanthes spp. em diferentes regiões produtoras, foi estimada por meio de difusão enzimática em meio específico e mensuração do halo de degradação de pectina. Em todos os isolados havia atividade pectinolítica, sendo divididos em cinco grupos distintos. Na maior parte dos isolados notou-se moderada atividade de pectinases. Em geral, isolados de Camapuã-MS tiveram menor diversidade genética para a produção de enzimas pécticas. Com base na atividade pectinolítica, isolados do patógeno foram selecionados e inoculados em genótipos de S. capitata (GC1081, GC1084, GC1086 e GC1094), S. scabra (GC1496) e S. macrocephala (GC1511), visando analisar a influência das pectinases na agressividade ao hospedeiro. Inicialmente, instalou-se ensaio de agressividade com os isolados CG656, CG657, CG687, CG706 e CG707, sendo constatada agressividade diferenciada apenas quando inoculados em S. scabra. Enquanto CG657, CG706 e CG707 foram os mais agressivos, CG656 foi o menos agressivo. Outro teste de agressividade avaliou os isolados CG768, CG769, CG772, CG775, CG779 e CG781. Estes se diferenciaram quanto à agressividade ao S. capitata (GC1081 e GC1094) e S. macrocephala (GC1511). Em geral, CG768 comportouse como pouco agressivo, enquanto que CG772, CG775 e CG781 como os mais agressivos. Para ambos, nos ensaios de agressividade, não se evidenciou aumento da severidade da antracnose com o aumento da atividade pectinolítica. Nas condições analisadas, a agressividade de C. gloeosporioides ao estilosantes não foi influenciada pelas enzimas pécticas.
\end{abstract}

Palavras-chave: Pectinases, enzimas degradadoras de parede celular, Glomerella cingulata, antracnose, variabilidade patogênica, estilosantes.

$\left({ }^{1}\right)$ Recebido para publicação em 12 de dezembro de 2006 e aceito em 12 de janeiro de 2009.

$\left({ }^{2}\right)$ Laboratório Nacional Agropecuário (Lanagro/SP/MAPA), Caixa Postal 13208-051 Jundiaí (SP). E-mail: carlos.marchi@agricultura.gov.br $\left(^{*}\right)$ Autor correspondente.

$\left({ }^{3}\right)$ Laboratório de Fitopatologia, Embrapa Gado de Corte, Caixa Postal 154, 79002-970 Campo Grande (MS).

$\left({ }^{4}\right)$ Universidade para o Desenvolvimento do Estado e da Região do Pantanal (UNIDERP), Campo Grande (MS), Caixa Pos tal 2153, 79003-010 Campo Grande (MS).

$\left({ }^{5}\right)$ Acadêmica de Ciências Biológicas da Universidade para o Desenvolvimento do Estado e da Região do Pantanal (UNIDERP).

$\left(^{6}\right)$ Mestranda, Universidade Federal de Mato Grosso do Sul, Caixa Postal 549, 79070-900 Campo Grande (MS). 


\title{
ABSTRACT \\ PECTINOLYTIC ACTIVITY OF COLLETOTRICHUM GLOEOSPORIOIDES AND ITS RELATIONSHIP WITH AGGRESSIVENESS TO STYLOSANTHES SPP.
}

\begin{abstract}
Pectinolytic activity of 40 isolates of Colletotrichum gloeosporioides obtained from Stylosanthes spp.lesions, in distinct producing regions, was estimated through the enzymatic diffusion in pectin-medium free of glucose, and measured by pectin degradation. All isolates showed pectinolytic activity, and were divided in five groups. Moderate production of pectic enzymes was evidenced in the majority of the isolates. In general, isolates from Camapua-MS presented low genetic diversity for the production of pectinases. Taking into account the activity of pectinases, isolates of the pathogen were selected and inoculated in S. capitata (GC1081, GC1084, GC1086 and GC1094), S. scabra (GC1496) and S. macrocephala (GC1511). Thus, the enzyme influence on aggressiveness to the host was evaluated. Initially, aggressiveness test was installed with the isolates CG656, CG657, CG687, CG706 and CG707. Differences in aggressiveness were observed only when the isolates were inoculated in S. scabra. The isolates CG657, CG706 and CG707 were the most aggressive, and CG656 was the least aggressive. Another aggressiveness test was established to evaluate the isolates CG768, CG769, CG772, CG775, CG779 and CG781. These isolates showed differences in their aggressiveness when inoculated in S. capitata (GC1081 and GC1094) and S. macrocephala (GC1511). In general, CG768 exhibited the lowest while, CG772, CG775 and CG781 the highest aggressiveness. In both aggressiveness tests, there were no evidences for a direct correlation of anthracnose increase in severity with the of the pectinolytic activity. For the conditions evaluated, the pectic enzymes did not influence the aggressiveness of $C$. gloeosporioides to the stylo.
\end{abstract}

Key words: Pectinases, cell wall degrading enzymes, Glomerella cingulata, anthracnose, pathogenic variability, stylo.

\section{INTRODUÇÃO}

Estilosantes, Stylosanthes sp. (Aublet) SwarTz, constitui importante fabácea forrageira tropical, sobretudo em áreas de solos ácidos e de baixa fertilidade, podendo ser utilizado como banco de proteína ou em consorciação com poáceas (FERNANDES, 2003). Apesar do grande potencial, o uso comercial de Stylosanthes sp. tem sido limitado pela antracnose, a mais importante e disseminada doença dessa forrageira (CHARCHAR et al., 2002; FERNANDES, 2003). A antracnose afeta o estabelecimento, o crescimento, a produção de sementes e a persistência de praticamente todas as espécies de Stylosanthes.

Colletotrichum gloeosporioides (Penz.) Penz. e SACC., forma anamórfica de Glomerella cingulata (Stonem.) Spauld. e Scherenk., é o principal agente causal da antracnose. Tal patógeno incita dois tipos de sintomas distintos, tipos A e B (CHAKRABORTY et al., 1988). O sintoma tipo A caracteriza-se pela ocorrência de lesões marrom-claras a cinzas e margens escuras em caules, folíolos e inflorescências. Já o sintoma tipo B, observado apenas em S. guianensis (AUBLET) SwARTZ, é caracterizado por necrose geral, sem margem definida, em caules e folíolos.

Isolados de C. gloeosporioides, coletados em diferentes regiões do Brasil, principal centro de origem e diversidade de estilosantes, possuem alta variabilidade patogênica, constituindo diferentes grupos quando caracterizados por meio de técnicas moleculares (CHAKRABORTY et al., 1997). Tal variabilidade do patógeno implica grande risco à utilização de novas cultivares da forrageira, fato constatado anteriormente no Brasil e na Colômbia, onde a antracnose inviabilizou o cultivo de cinco de oito cultivares de Stylosanthes spp. (MiLes et al., 1997).

Acredita-se que enzimas hidrolíticas secretadas por C. gloeosporioides atuam na interação com Stylosanthes spp., visto o amplo arsenal enzimático produzido por Colletotrichum spp., o qual é capaz de destruir componentes estruturais de tecidos da planta, e em alguns casos, culminar com a morte celular (BAiley et al., 1992). É provável que, durante a patogênese, essas enzimas favoreçam a penetração, a colonização, a obtenção de nutrientes e/ou contribuam para interferir nas reações de defesa do hospedeiro (Pascholati et al., 1995; AnNis e Goodwin, 1997).

Atividade enzimática extracelular tem sido demonstrada em C. gloeosporioides. Em isolados de abacateiro, cajueiro, mamoeiro, mangueira e maracujazeiro, por exemplo, constataram-se atividades pectinolítica (YАКОВY et al., 2001), cutinolítica (DickMAn e PATIL, 1986), amilolítica, lipolítica, proteolítica e celulolítica (Assis et al., 2001; Lima FilHo et al., 2003). Em alguns casos, evidências têm sugerido a contribuição dessas enzimas na patogênese do fungo, a exemplo das atividades de cutinases e de pectato liase (PEL), cuja importância para o desenvolvimento da antracnose em frutos de mamão (DickMAn e PATIL, 1986) e abacate (YАKOBY et al., 2001), respectivamente, foi demonstrada. 
Não foram anotados relatos sobre a diferenciação enzimática, especificamente quanto à produção de pectinases, entre isolados de $C$. gloeosporioides oriundos de Stylosanthes spp. Essas enzimas, as quais degradam a pectina, principal componente da parede celular primária e da lamela média, têm sido alvos de intensas pesquisas, por se acreditar que constituem importantes fatores de patogenicidade/ agressividade (ANNIS e Goodwin, 1997). Assim, objetivou-se analisar isolados de $C$. gloeosporioides, provenientes de Stylosanthes spp., quanto à atividade pectinolítica e sua correlação com a agressividade ao hospedeiro.

\section{MATERIAL E MÉTODOS}

\section{Isolados do fungo}

Foram utilizados 40 isolados monospóricos de C. gloeosporioides, pertencentes à coleção do Laboratório de Fitopatologia da Embrapa Gado de Corte, Campo Grande (MS). A origem e o ano de coleta dos isolados, designados pelo prefixo CG, estão descritos na tabela 1.

Os isolados foram rotineiramente cultivados em meio aveia-ágar (AA), e mantidos a $28{ }^{\circ} \mathrm{C}$ e fotoperíodo de 12 horas. Para preservação em longo prazo, discos de micélio foram mantidos em frascos de penicilina contendo óleo mineral estéril, a $25{ }^{\circ} \mathrm{C}$.

\section{Atividade pectinolítica in vitro}

A atividade pectinolítica de $C$. gloeosporioides foi estimada em ensaio de difusão em meio sólido contendo pectina, instalado em delineamento inteiramente casualizado. Discos $(6$ $\mathrm{mm}$ de diâmetro) de AA contendo micélio dos isolados fúngicos foram transferidos para placas de Petri com $25 \mathrm{~mL}$ de meio mineral tamponado (MMT) [2 g de $\mathrm{KH}_{2} \mathrm{PO}_{4} ; 7 \mathrm{~g}$ de $\mathrm{K}_{2} \mathrm{HPO}_{4} ; 1 \mathrm{~g}$ de $\left(\mathrm{NH}_{4}\right)_{2} \mathrm{SO}_{4} ; 1$ $\mathrm{g}$ de $\mathrm{MgSO}_{4} .7 \mathrm{H}_{2} \mathrm{O} ; 0,6 \mathrm{~g}$ de extrato de levedura; 13 g de ágar; $1 \mathrm{~L}$ de $\mathrm{H}_{2} \mathrm{O}$ destilada; $\mathrm{pH}=7,2$ ] suplementado com pectina $\left(3 \mathrm{~g} \mathrm{~L}^{-1}\right)$. Foram preparadas quatro réplicas (placas) por isolado, as quais permaneceram a $28{ }^{\circ} \mathrm{C}$ e fotoperíodo de 12 horas por sete dias. A capacidade dos isolados em crescer em MMT suplementado com pectina foi avaliada por meio da área da colônia micelial (ACM), calculada após mensuração do diâmetro médio da colônia e aplicação da fórmula $\mathrm{ACM}=\pi$ $\mathrm{xd}^{2} / 4\left(\mathrm{~cm}^{2}\right)$.
Em seguida, a partir de cada repetição, foi transferido disco (6 mm de diâmetro) de MMT com micélio para placa de Petri com $25 \mathrm{~mL}$ de meio Mac Ilvaine $(7,74 \mathrm{~g}$ de ácido cítrico; $17,93 \mathrm{~g}$ de $\mathrm{Na}_{2} \mathrm{HPO}_{4} ; 2,5 \mathrm{~g}$ de pectina cítrica; $13 \mathrm{~g}$ de ágar; 1 $\mathrm{L}$ de $\mathrm{H}_{2} \mathrm{O}$ destilada; $\mathrm{pH}=6,0$ ), o qual permitiu a difusão das pectinases para o meio circundante. Essas placas foram mantidas a $40{ }^{\circ} \mathrm{C}$ por 48 horas. Decorrido o tempo, foram vertidos $3 \mathrm{~mL}$ de solução lugol (5 g de KI; $1 \mathrm{~g}$ de iodo; $100 \mathrm{~mL}$ de $\mathrm{H}_{2} \mathrm{O}$ destilada) sobre as placas. Após 20 minutos de repouso, essa solução foi descartada. Posteriormente, a área do halo de degradação da pectina (AHDP) foi visualizada conforme descrito por Hankin e ANAGNOSTAKIs (1975) e calculada segundo MARCHI et al. (2006).

\section{Teste de agressividade de C. gloeosporioides a genótipos de estilosantes}

Foram utilizadas plantas de estilosantes, correspondente às hospedeiras diferenciais GC1081, GC1084, GC1086, GC1094 (S. capitata), GC1496 (S. scabra) e GC1511 (S. macrocephala), com cerca de seis semanas de idade, as quais foram cultivadas em tubetes em casa de vegetação.

Dois ensaios foram instalados, sendo o primeiro desenvolvido com os isolados CG656, CG657, CG687, CG706 e CG707, e o segundo com CG768, CG769, CG772, CG775, CG779 e CG781. Suspensões de inóculo dos referidos isolados foram obtidas, e ajustadas para a concentração de 1,0 x $10^{6}$ conídios / $\mathrm{mL}$. Logo após, procedeu-se a pulverização das plantas até a cobertura completa dos folíolos, sem haver escorrimento. Utilizou-se delineamento de blocos casualizados com sete repetições de 10 plantas, em esquema fatorial. Após a inoculação, as plantas

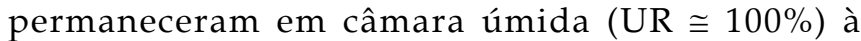
temperatura ambiente por 48 horas. Posteriormente, foram transferidas para bancadas em sala de incubação à mesma temperatura e iluminação natural (CHAKRABORTY et al., 2002). Após 12 dias, avaliou-se a severidade (SEV) da antracnose, com base na escala diagramática proposta por CHAKRABORTY (1990).

A agressividade dos isolados foi estimada pela média da severidade da antracnose observada nos diferentes genótipos de estilosantes. A reação dos genótipos à C. gloeosporioides, por outro lado, foi avaliada pela média da severidade da doença incitada pelos diferentes isolados do patógeno. Com base no grau de resistência ao patógeno, os genótipos foram classificados segundo FERNANDES (2003), a saber: 1 imune $(\mathrm{SEV}=0) ; 2$ - altamente resistente $(0<\mathrm{SEV}=2)$; 3 - resistente $(2<\mathrm{SEV}=4) ; 4$ - suscetível $(4<\mathrm{SEV}$ $=7)$, e 5 - altamente suscetível (SEV > 7). 
Tabela 1. Atividade pectinolítica de isolados de Colletotrichum gloeosporioides, provenientes de Stylosanthes spp. cultivado em diferentes regiões e safras, estimada por meio da área do halo de degradação da pectina (AHDP) em meio sólido Mac Ilvaine $(\mathrm{pH}=6,0)$

\begin{tabular}{|c|c|c|c|}
\hline Isolado (CG) & Hospedeiro & Local / Ano de Coleta & $\operatorname{AHDP}\left(\mathrm{cm}^{2}\right)$ \\
\hline 002 & Stylosanthes capitata & Campo Grande, MS / 1994 & 7,00 a \\
\hline 020 & S. capitata & Planaltina, DF / 1994 & $2,27 \mathrm{~b}$ \\
\hline 656 & S. capitata & Campo Grande, MS / 2002 & $2,55 \mathrm{~b}$ \\
\hline 657 & S. capitata & Campo Grande, MS / 2003 & $1,85 \mathrm{c}$ \\
\hline 672 & S. capitata & Campo Grande, MS / 2003 & $2,06 \mathrm{c}$ \\
\hline 687 & S. capitata & Campo Grande, MS / 2003 & $1,44 \mathrm{~d}$ \\
\hline 706 & S. capitata & Campo Grande, MS / 2003 & $1,63 \mathrm{~d}$ \\
\hline 707 & S. capitata & Campo Grande, MS / 2003 & $2,08 \mathrm{c}$ \\
\hline 722 & S. capitata & Chapadão do Sul, MS / 2004 & $1,35 \mathrm{~d}$ \\
\hline 730 & S. capitata & Campo Grande, MS / 2004 & $1,16 \mathrm{~d}$ \\
\hline 731 & S. capitata & Chapadão do Sul, MS / 2004 & $1,59 \mathrm{~d}$ \\
\hline 734 & S. capitata & Chapadão do Sul, MS / 2004 & $0,29 \mathrm{e}$ \\
\hline 743 & S. capitata & Campo Grande, MS / 2004 & $1,66 \mathrm{~d}$ \\
\hline 745 & S. capitata & Camapuã, MS / 2004 & $2,74 \mathrm{~b}$ \\
\hline 768 & S. capitata & Chapadão do Sul, MS / 2005 & $2,02 \mathrm{c}$ \\
\hline 769 & S. capitata & Chapadão do Sul, MS / 2005 & $2,19 b$ \\
\hline 772 & S. capitata & Chapadão do Sul, MS / 2005 & $2,03 \mathrm{c}$ \\
\hline 775 & S. capitata & Chapadão do Sul, MS / 2005 & $1,74 \mathrm{c}$ \\
\hline 777 & S. macrocephala & Chapadão do Sul, MS / 2005 & $1,91 \mathrm{c}$ \\
\hline 779 & S. capitata & Chapadão do Sul, MS / 2005 & $2,22 \mathrm{~b}$ \\
\hline 781 & S. capitata & Chapadão do Sul, MS / 2005 & $2,20 \mathrm{~b}$ \\
\hline 787 & S. macrocephala & Chapadão do Sul, MS / 2005 & $1,35 \mathrm{~d}$ \\
\hline 803 & S. capitata & Campo Grande, MS / 2006 & $2,27 \mathrm{~b}$ \\
\hline 806 & S. capitata & Camapuã, MS / 2006 & $1,80 \mathrm{c}$ \\
\hline 809 & S. capitata & Chapadão do Sul, MS / 2006 & $1,93 \mathrm{c}$ \\
\hline 811 & S. capitata & Campo Grande, MS / 2006 & $1,69 \mathrm{~d}$ \\
\hline 812 & S. capitata & Chapadão do Sul, MS / 2006 & $2,29 \mathrm{~b}$ \\
\hline 813 & S. capitata & Campo Grande, MS / 2006 & $1,89 \mathrm{c}$ \\
\hline 815 & S. capitata & Camapuã, MS / 2006 & $1,95 \mathrm{c}$ \\
\hline 817 & S. capitata & Chapadão do Sul, MS / 2006 & $1,81 \mathrm{c}$ \\
\hline 819 & S. capitata & Camapuã, MS / 2006 & $1,83 \mathrm{c}$ \\
\hline 826 & S. capitata & Camapuã, MS / 2006 & $1,59 \mathrm{~d}$ \\
\hline 831 & S. capitata & Camapuã, MS / 2006 & $1,93 \mathrm{c}$ \\
\hline 833 & S. capitata & Camapuã, MS / 2006 & $1,78 \mathrm{c}$ \\
\hline 839 & S. capitata & Camapuã, MS / 2006 & $1,77 \mathrm{c}$ \\
\hline 845 & S. capitata & Campo Grande, MS / 2006 & $2,02 \mathrm{c}$ \\
\hline 854 & S. capitata & Chapadão do Sul, MS / 2006 & $1,89 \mathrm{c}$ \\
\hline 855 & S. capitata & Chapadão do Sul, MS / 2006 & $1,73 \mathrm{c}$ \\
\hline 863 & S. capitata & Chapadão do Sul, MS / 2006 & $1,79 \mathrm{c}$ \\
\hline 875 & S. capitata & Chapadão do Sul, MS / 2006 & $1,47 \mathrm{~d}$ \\
\hline
\end{tabular}

Médias seguidas pela mesma letra não diferem entre si pelo Teste de Agrupamento Scott-Knott $(\mathrm{P} \geq 0,05)$. 
Atividade pectinolítica de C. gloeosporioides vs. agressividade a genótipos de estilosantes

Para verificar a existência de correlação entre a atividade pectinolítica de C. gloeosporioides e a agressividade em plantas de estilosantes, foram utilizados os valores médios da produção de enzimas pécticas pelos diferentes isolados, estimada pela AHDP, e os respectivos valores médios de severidade da antracnose em cada genótipo analisado.

\section{Análise dos dados}

As pressuposições da análise de variância foram verificadas por meio de testes de homogeneidade de variância, normalidade e padrão de distribuição de resíduos. Os procedimentos estatísticos, análises de variância, correlação de Pearson e testes de média foram realizados com os programas SAS (2002) e Genes (CRUZ, 2001). Para efeito de análise, as notas atribuídas para a severidade da antracnose foram transformadas para $\sqrt{\left(\begin{array}{ll}x & 0,01\end{array}\right)}$.

\section{RESULTADOS E DISCUSSÃO}

\section{Caracterização pectinolítica de $C$. gloeosporioides in vitro}

Todos os isolados de C. gloeosporioides foram capazes de crescer em meio contendo pectina como fonte de carbono, o que indicou a habilidade do agente causal da antracnose em Stylosanthes spp. em produzir pectinases. Após 48 horas de cultivo, já foi possível detectar crescimento micelial em MMT suplementado com pectina. Quando se analisou a área da colônia micelial aos sete dias de incubação no referido meio de cultura, constatou-se que os isolados foram agrupados em seis categorias (dados não ilustrados). O maior crescimento micelial foi verificado pelos isolados CG819, CG826 e CG833 $\left(63,6 \mathrm{~cm}^{2}\right)$, enquanto o menor crescimento, por CG812 e CG817 $\left(12,8\right.$ a $\left.18,7 \mathrm{~cm}^{2}\right)$.

Halos de degradação de pectina foram observados em todas as placas de cultivo dos isolados, confirmando a capacidade de patógeno em sintetizar pectinases. Esta alta freqüência de isolados com atividade enzimática sugeriu a importância das pectinases em alguma fase do ciclo de vida de C. gloeosporioides. Almeida e COÊLHo (2007) testaram a habilidade de isolados de C. gloeosporioides recuperados de maracujá amarelo em produzir pectinases, porém a metodologia utilizada não permitiu a detecção da atividade enzimática avaliada. Por outro lado, Maccheroni Júnior et al. (2004) relataram a produção de pectinases em isolados de $C$. gloeosporioides endofíticos e patogênicos à laranja doce, assim como em isolados entomopatogênicos.

O ensaio de difusão em meio específico permitiu constatar a variabilidade intraespecífica do patógeno quanto à produção pectinolítica. De acordo com o teste de agrupamento, embasado na AHDP, os isolados foram diferenciados em cinco grupos, os quais foram aqui definidos como excelentes (CG002, com AHDP de 7,00 $\mathrm{cm}^{2}$ ), bons (CG020, CG656, CG745, CG769, CG779, CG781, CG803 e CG812, com AHDP de 2,19 a 2,74 $\mathrm{cm}^{2}$ ), moderados (CG657, CG672, CG707, CG768, CG772, CG775, CG777, CG806, CG809, CG813, CG815, CG817, CG819, CG831, CG833, CG839, CG845, CG854, CG863 e CG855, com AHDP de 1,73 a 2,10 $\mathrm{cm}^{2}$ ), maus (CG687, CG706, CG722, CG730, CG731, CG743, CG787, CG811, CG826 e CG875, com AHDP de 1,16 a $1,69 \mathrm{~cm}^{2}$ ) e péssimos (CG734, com AHDP de $0,29 \mathrm{~cm}^{2}$ ) produtores de pectinases (Tabela 1 ).

Na maior parte dos isolados (50\%), a atividade pectinolítica foi moderada. Nas condições in vitro analisadas, apenas CG002 foi considerado excelente produtor de pectinases. Da mesma forma, apenas em um isolado, CG734, a atividade pectinolítica foi péssima. Ambos os isolados foram recuperados de plantas de S. capitata (Tabela 1).

Não se constatou correlação entre o crescimento micelial em MMT suplementado com pectina e a atividade pectinolítica $(\mathrm{r}=-0,15 ; \mathrm{P}=0,07)$.

Analisando os isolados de $C$. gloeosporioides em função do local de coleta, observou-se maior variabilidade pectinolítica entre aqueles provenientes de Campo Grande-MS ou Chapadão do Sul-MS, os quais formaram três grupos (Tabela 2).

Em contrapartida, constatou-se baixa diversidade genética para a expressão desse marcador bioquímico entre os isolados oriundos de Camapuã-MS. Embora se tenha analisado pequeno número de isolados e um único marcador, a imensa variabilidade genética de populações de $C$. gloeosporioides da América do Sul (ChAKRABORTy et al., 1997; MANNERS e HE, 1997) permitiria supor que haveria uma maior variação na produção de pectinases. Estudos futuros, sobretudo envolvendo técnicas moleculares, são necessários para caracterizar isolados de diferentes procedências do Brasil, inclusive porque a expressão de pectinases é apenas uma das muitas estratégias bioquímicas de ataque de C. gloeosporioides. 
Tabela 2. Atividade pectinolítica de isolados de Colletotrichum gloeosporioides patogênicos à Stylosanthes spp., estimada por meio da área do halo de degradação da pectina (AHDP) em meio sólido Mac Ilvaine $(\mathrm{pH}=6,0)$ e analisada em função do local de coleta

\begin{tabular}{|c|c|c|c|}
\hline \multirow{2}{*}{$\begin{array}{l}\text { Local de Coleta } \\
\text { Camapuã, MS }\end{array}$} & \multirow{2}{*}{$\begin{array}{c}\text { Isolado (CG) } \\
745\end{array}$} & \multicolumn{2}{|c|}{$\operatorname{AHDP}\left(\mathrm{cm}^{2}\right)$} \\
\hline & & $2,74^{1}$ & a \\
\hline & 806 & 1,80 & $\mathrm{~b}$ \\
\hline & 815 & 1,95 & $\mathrm{~b}$ \\
\hline & 819 & 1,83 & $b$ \\
\hline & 826 & 1,59 & $\mathrm{~b}$ \\
\hline & 831 & 1,93 & $\mathrm{~b}$ \\
\hline & 833 & 1,78 & $\mathrm{~b}$ \\
\hline & 839 & 1,77 & $\mathrm{~b}$ \\
\hline \multirow[t]{13}{*}{ Campo Grande, MS } & 002 & 7,00 & $\mathrm{a}$ \\
\hline & 656 & 2,55 & $\mathrm{~b}$ \\
\hline & 657 & 1,85 & $\mathrm{~b}$ \\
\hline & 672 & 2,06 & $\mathrm{~b}$ \\
\hline & 687 & 1,44 & $\mathrm{C}$ \\
\hline & 706 & 1,63 & $\mathrm{C}$ \\
\hline & 707 & 2,08 & $\mathrm{~b}$ \\
\hline & 730 & 1,16 & c \\
\hline & 743 & 1,66 & $\mathrm{C}$ \\
\hline & 803 & 2,27 & $b$ \\
\hline & 811 & 1,69 & c \\
\hline & 813 & 1,89 & $\mathrm{~b}$ \\
\hline & 845 & 2,02 & $\mathrm{~b}$ \\
\hline \multirow[t]{18}{*}{ Chapadão do Sul, MS } & 722 & 1,35 & $\mathrm{~b}$ \\
\hline & 731 & 1,59 & $\mathrm{~b}$ \\
\hline & 734 & 0,29 & $\mathrm{c}$ \\
\hline & 768 & 2,02 & $\mathrm{a}$ \\
\hline & 769 & 2,19 & $\mathrm{a}$ \\
\hline & 772 & 2,03 & $\mathrm{a}$ \\
\hline & 775 & 1,74 & $\mathrm{~b}$ \\
\hline & 777 & 1,91 & $\mathrm{a}$ \\
\hline & 779 & 2,22 & $\mathrm{a}$ \\
\hline & 781 & 2,20 & $\mathrm{a}$ \\
\hline & 787 & 1,35 & $\mathrm{~b}$ \\
\hline & 809 & 1,93 & $\mathrm{a}$ \\
\hline & 812 & 2,29 & $\mathrm{a}$ \\
\hline & 817 & 1,81 & $\mathrm{~b}$ \\
\hline & 854 & 1,89 & $\mathrm{a}$ \\
\hline & 855 & 1,73 & $\mathrm{~b}$ \\
\hline & 863 & 1,79 & $\mathrm{~b}$ \\
\hline & 875 & 1,47 & $b$ \\
\hline
\end{tabular}

Para cada local de coleta, médias seguidas pela mesma letra não diferem entre si pelo Teste de Agrupamento Scott-Knott $(P \geq 0,05)$.
Agressividade de C. gloeosporioides a genótipos de estilosantes

Com base nos resultados da caracterização pectinolítica in vitro de C. gloeosporioides (Tabela 1), instalou-se teste de agressividade envolvendo os isolados CG656 (bom produtor de pectinases), CG657 e CG707 (moderados produtores de pectinases) e CG687 e CG706 (maus produtores de pectinases) e plântulas de $S$. capitata, S. macrocephala e S. scabra (Tabela 3). Em nenhum caso, nos genótipos de estilosantes, observou-se reação característica de suscetibilidade, visto que a severidade da antracnose não ultrapassou o índice de 25\% (nota para SEV = 4) (Tabela 3). Segundo Fernandes (2003), genótipos de estilosantes com severidade de antracnose inferior a $25 \%$ são considerados com grau de resistência satisfatório, pois, apesar da ocorrência de manchas foliares, não se evidencia desfolha.

Pela análise de variância, notaram-se diferenças significativas para os efeitos de isolados e hospedeiros, mas não para sua interação. Evidenciouse que os isolados CG707, CG657 e CG706 foram os mais agressivos ao estilosantes, independentemente da espécie hospedeira. Em contrapartida, a inoculação de CG656 resultou em menor índice de severidade de antracnose (Tabela 3). Quanto à reação dos hospedeiros ao C. gloeosporioides, independentemente do isolado, observaram-se os menores índices de severidade da doença nos genótipos GC1086, GC1094, ambos pertencentes à espécie S. capitata, e GC1511, correspondente à S. macrocephala. Em termos absolutos gerais, maior porcentagem de tecido foliar lesionado foi constatada no genótipo GC1496, correspondente à S. scabra.

Um segundo teste de agressividade foi instalado, envolvendo os isolados CG769, CG779, CG781, com boa atividade pectinolítica, CG768, CG772 e CG775, considerados moderados produtores de pectinases e plântulas de S. capitata, S. macrocephala e S. scabra (Tabela 4). No geral, foram constatados índices de severidade da antracnose superiores aos observados no ensaio anterior. Contudo, neste segundo ensaio, também não se observou interação significativa entre os efeitos de isolados e hospedeiros.

Pelos resultados, CG772, CG775 e CG781 são os isolados mais agressivos, os quais não se destacaram de CG769 e CG779 (Tabela 4). Em termos absolutos gerais, evidenciou-se menor agressividade no isolado CG768.

Quanto à resposta de estilosantes à antracnose, com base na classificação aplicada por FERNANDES (2003), constatou-se suscetibilidade nos genótipos GC1086 e GC1496 (Tabela 4). 
Tabela 3. Interação de diferentes isolados de Colletotrichum gloeosporioides, recuperados de folíolos lesionados de Stylosanthes capitata, e genótipos de estilosantes. (Ensaio 1)

\begin{tabular}{|c|c|c|c|c|c|c|c|}
\hline \multirow{2}{*}{ Isolado (CG) } & \multicolumn{6}{|c|}{ Hospedeiro (GC) ${ }^{(1)}$} & \multirow{2}{*}{ Agressividade do isolado ${ }^{(4)}$} \\
\hline & 1081 & 1084 & 1086 & 1094 & 1496 & 1511 & \\
\hline 656 & $0,43^{(2)}$ & 1,29 & 0,00 & 0,00 & 0,14 & 0,00 & $0,31^{(5)} \mathrm{C}$ \\
\hline 657 & 1,71 & 2,57 & 2,57 & 2,14 & 3,14 & 1,86 & $2,33 \mathrm{a}$ \\
\hline 687 & 0,71 & 0,29 & 0,71 & 0,57 & 1,29 & 1,43 & $0,83 \mathrm{bc}$ \\
\hline 706 & 1,14 & 2,14 & 1,29 & 1,14 & 2,00 & 1,14 & $1,48 a b$ \\
\hline 707 & 3,29 & 2,43 & 1,57 & 2,00 & 3,71 & 1,86 & $2,48 \mathrm{a}$ \\
\hline $\begin{array}{l}\text { Reação do } \\
\text { hospedeiro }\end{array}$ & $1,46^{5} \mathrm{ab}$ & $1,74 \mathrm{ab}$ & $1,23 \mathrm{~b}$ & $1,17 \mathrm{~b}$ & 2,06 a & $1,26 a b$ & - \\
\hline
\end{tabular}

( $\left.{ }^{1}\right)$ Genótipos GC1081, GC1084, GC1086, GC1094 (S. capitata), GC1496 (S. scabra) e GC1511 (S. macrocephala).

$\left({ }^{2}\right)$ Nota atribuída à severidade da antracnose, de acordo com a escala diagramática de CHAKRABORTY (1990).

$\left({ }^{3}\right)$ Estimada com base na média das notas de severidade da antracnose causada pelos diferentes isolados.

$\left({ }^{4}\right)$ Estimada com base na média das notas de severidade da antracnose observada nos diferentes genótipos.

$\left({ }^{5}\right)$ Valores seguidos pela mesma letra não diferem entre si pelo teste de Tukey $(P \geq 0,05)$.

Tabela 4. Interação de diferentes isolados de Colletotrichum gloeosporioides, recuperados de folíolos lesionados de Stylosanthes capitata, e genótipos de estilosantes. (Ensaio 2)

\begin{tabular}{|c|c|c|c|c|c|c|c|}
\hline \multirow{2}{*}{ solado (CG) } & \multicolumn{6}{|c|}{ Hospedeiro (GC) ${ }^{(1)}$} & \multirow{2}{*}{ Agressividade do isolado ${ }^{(4)}$} \\
\hline & 1081 & 1084 & 1086 & 1094 & 1496 & 1511 & \\
\hline 768 & $0,86^{(2)}$ & 1,86 & 3,86 & 0,86 & 6,57 & 0,86 & $2,48^{(5)} \mathrm{b}$ \\
\hline 769 & 2,86 & 2,43 & 4,00 & 3,71 & 5,71 & 2,43 & $3,52 \mathrm{ab}$ \\
\hline 772 & 5,86 & 3,71 & 4,57 & 4,86 & 5,86 & 5,14 & $5,00 \mathrm{a}$ \\
\hline 775 & 3,00 & 4,57 & 4,86 & 5,57 & 6,14 & 2,71 & $4,48 \mathrm{a}$ \\
\hline 779 & 2,43 & 3,43 & 3,57 & 3,86 & 4,57 & 1,86 & $3,29 \mathrm{ab}$ \\
\hline 781 & 4,57 & 3,14 & 5,43 & 4,86 & 4,29 & 1,71 & $4,00 \mathrm{a}$ \\
\hline $\begin{array}{l}\text { Reação } \\
\text { do hospedeir }\end{array}$ & $3,26^{(5)} b c$ & $3,19 \mathrm{bc}$ & $4,38 \mathrm{ab}$ & $3,95 \mathrm{abc}$ & $5,52 \mathrm{a}$ & $2,45 \mathrm{c}$ & - \\
\hline
\end{tabular}

( $\left.{ }^{1}\right)$ Genótipos GC1081, GC1084, GC1086, GC1094 (S. capitata), GC1496 (S. scabra) e GC1511 (S. macrocephala).

$\left({ }^{2}\right)$ Nota atribuída à severidade da antracnose, de acordo com a escala diagramática de CHAKRABORTY (1990).

$\left({ }^{3}\right)$ Estimada com base na média das notas de severidade da antracnose causada pelos diferentes isolados.

$\left({ }^{4}\right)$ Estimada com base na média das notas de severidade da antracnose observada nos diferentes genótipos.

$\left(^{5}\right)$ Valores seguidos pela mesma letra não diferem entre si pelo teste de Tukey $(P \geq 0,05)$.

A reação do genótipo GC1496 ao patógeno, especificamente, foi similar à observada no primeiro ensaio de agressividade, ou seja, representou o maior índice de severidade da doença. A interação deste genótipo de S. scabra com os isolados CG768 ou CG775, em especial, resultou em porcentagem de tecido foliar lesionado/desfolha superior a $75 \%$. A suscetibilidade desse genótipo, lançado comercialmente na Austrália (cv. Fitzroy), foi relatada para as condições daquele país (DAvis et al., 1994) e do Brasil (FERNANDES, 2003). Segundo este último autor, o genótipo GC1496 constitui padrão de suscetibilidade para a antracnose.

Neste segundo ensaio de agressividade, GC1081, GC1084, GC1094, pertencentes à S. capitata, e GC 1511, correspondente à S. macrocephala tiveram resistência satisfatória à antracnose (Tabela 4). Este último genótipo foi o de menor índice de severidade da doença (SEV < 7\%). No ensaio anterior, neste hospedeiro também se notou baixo índice de doença (Tabela 3). O bom desempenho do genótipo de $S$. macrocephala ante $C$. gloeosporioides está de acordo com as informações da literatura. Por exemplo, os níveis baixos de antracnose na cv. Estilosantes Campo Grande, mistura física de sementes de $S$. capitata e $S$. macrocephala, observados em condições de campo, foram atribuídos ao alto grau de resistência dos componentes de S. macrocephala (Grof et al., 2001). CHARCHAR et al. (2002), também verificaram resposta de resistência à antracnose em todos os genótipos de S. macrocephala avaliados. 
Os ensaios de agressividade evidenciaram variabilidade entre os isolados de C. gloeosporioides oriundos de $S$. capitata (Tabelas 3 e 4). Alta variabilidade para a agressividade tem sido relatada para os isolados de C. gloeosporioides coletados em regiões do Brasil (CHAKRABORTY et al., 1997, 2002; FERnANDES, 2003). Segundo ChAKRABORTy et al. (1997), a variabilidade de C. gloeosporioides nos níveis patogênico e molecular é mais expressiva no Brasil do que em países como a Austrália, onde o patógeno e o hospedeiro foram introduzidos. Esse fenômeno é justificável, uma vez que o Brasil constitui o principal centro de origem e diversidade de estilosantes. Das 45 espécies descritas, 25 ocorrem naturalmente em várias regiões brasileiras (MiLEs et al., 1997), sendo possível verificar ampla variabilidade genética no nível inter ou intraespecífico (FERNANDES, 2003).

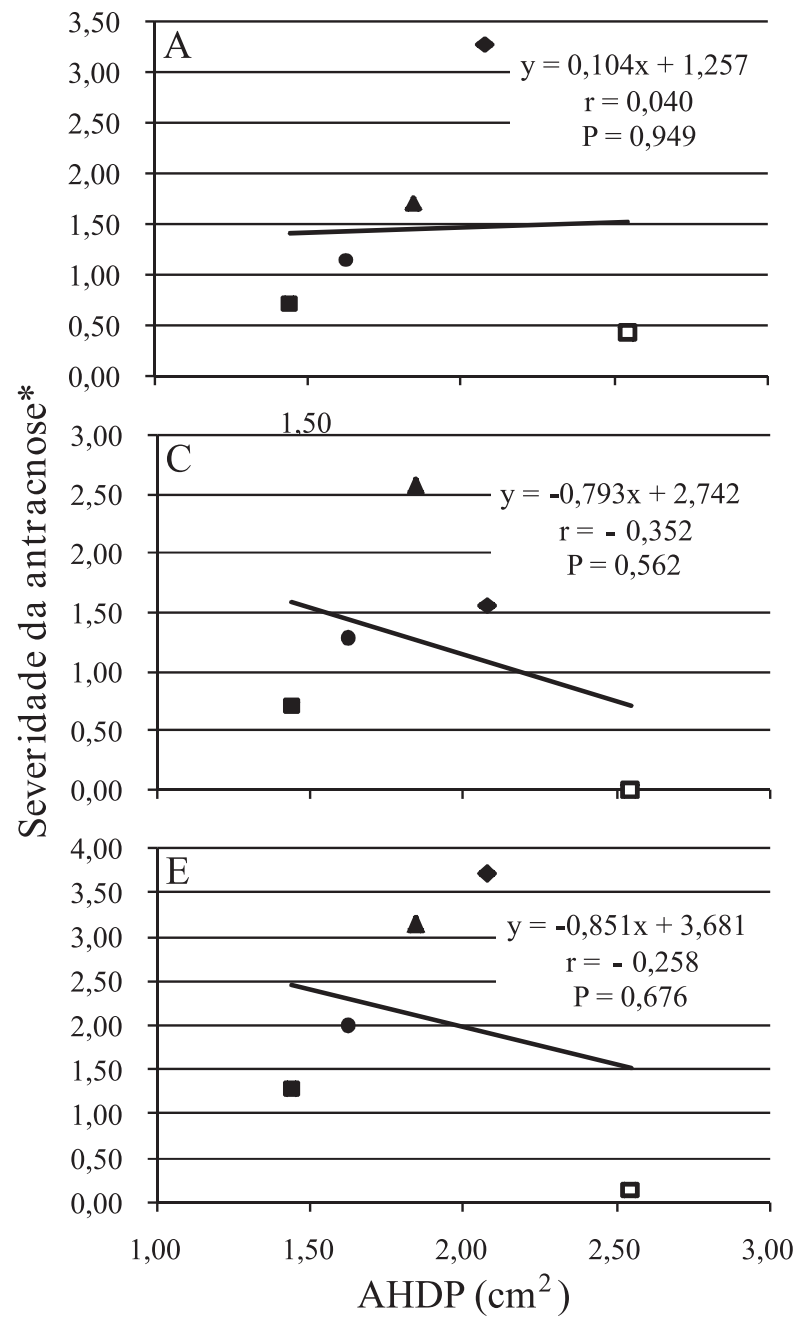

Atividade pectinolítica de C. gloeosporioides vs. agressividade a Stylosanthes spp.

Os resultados da correlação da atividade de pectinases em C. gloeosporioides e sua agressividade ao estilosantes estão representados nas Figuras 1 e 2. Com intuito de detectar possível especificidade do perfil pectinolítico dos isolados, endógenos de $S$. capitata, foram realizadas análises para cada hospedeiro. Tal especificidade foi suposta ocorrer na interação Alternaria solani e tomateiro (MARCHI et al., 2006). Apesar da moderada atividade pectinolítica, o conjunto de pectinases produzido pelo isolado AS6, endógeno de batateira, pareceu não favorecer sua agressividade em folíolos destacados ou plantas de tomateiro.

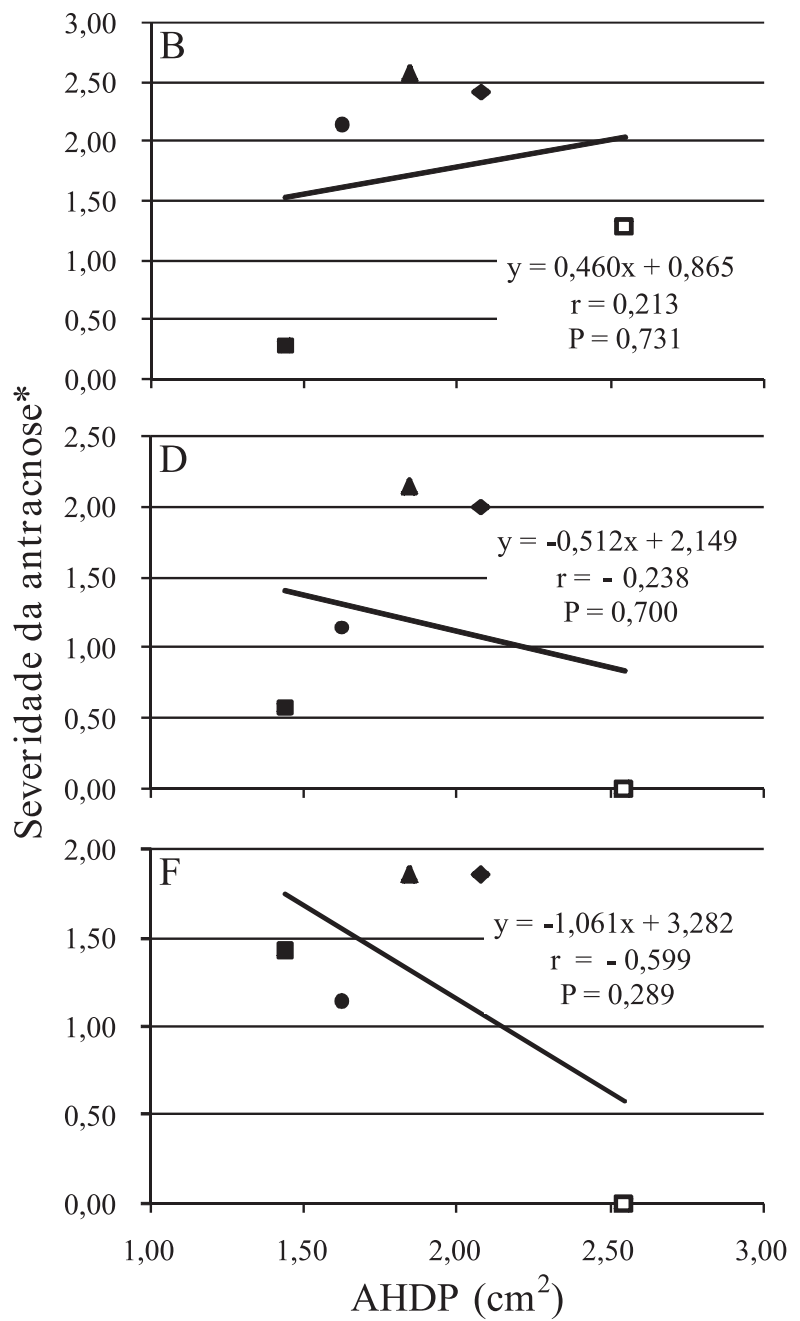

Figura 1. Atividade pectinolítica de isolados de Colletotrichum gloeosporioides, recuperados de folíolos lesionados de Stylosanthes capitata, estimada pela área do halo de degradação de pectina (AHDP) em meio sólido Mac Ilvaine (pH=6,0), e a relação com a agressividade à S. capitata, genótipos GC1081 (A), GC1084 (B), GC1086 (C) e GC1094 (D), S. scabra, genótipo GC1496 (E) e S. macrocephala, genótipo GC1511 (F), avaliada por meio da severidade da antracnose. (Ensaio

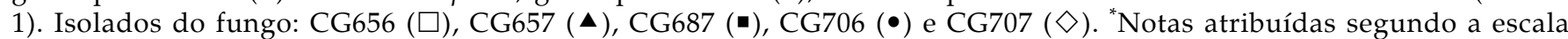
diagramática de CHAKRABORT (1990). 

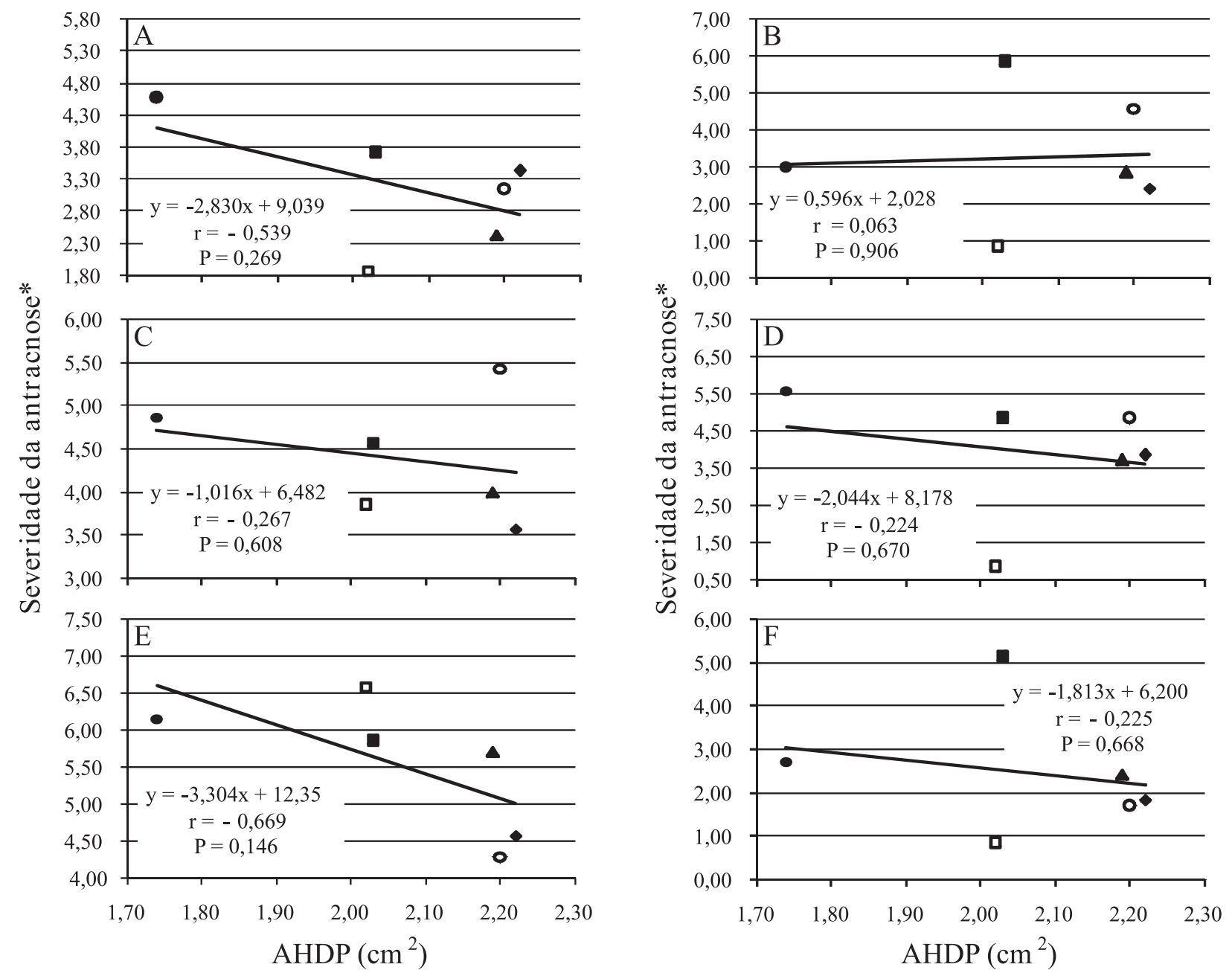

Figura 2. Atividade pectinolítica de isolados de Colletotrichum gloeosporioides, recuperados de folíolos lesionados de Stylosanthes capitata, estimada pela área do halo de degradação de pectina (AHDP) em meio sólido Mac Ilvaine (pH=6,0), e a relação com a agressividade à S. capitata, genótipos GC1081 (A), GC1084 (B), GC1086 (C) e GC1094 (D), S. scabra, genótipo GC1496 (E) e S. macrocephala, genótipo GC1511 (F), avaliada por meio da severidade da antracnose. (Ensaio

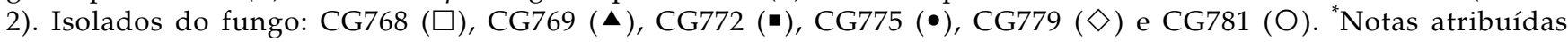
segundo a escala diagramática de CHAKRABORT (1990).

Nas condições estudadas, não se verificou correlação entre a atividade pectinolítica in vitro de C. gloeosporioides e sua agressividade nos diferentes genótipos de estilosantes. Em ambos os ensaios de agressividade, não se observou aumento dos índices de antracnose com o aumento da atividade pectinolítica (Figuras 1 e 2). Em S. capitata, assim como em S. macrocephala e S. scabra, a agressividade de $C$. gloeosporioides pareceu não ser influenciada pela atividade pectinolítica.

Já foram descritos vários genes codificando para enzimas pécticas no genoma de C. gloeosporioides (SHIH et al., 2000; YAKOBY et al., 2001; WEI et al., 2002). É possível que alguns desses genes sejam expressos apenas in planta, inclusive de forma diferenciada, dependente das condições do meio e/ou estágios do processo de infecção. Para o patossistema C. gloeosporioides f. sp. malvae e Malva pusilla, especificamente, a expressão de pnl-1 e pnl-2, genes que codificam para a síntese de pectina liase, foi detectada apenas na fase necrotrófica e em ambas as fases (biotrófica e necrotrófica) respectivamente (WEI et al., 2002). Tal complexidade, certamente, se refletiu nos resultados observados no patossistema $C$. gloeosporioides e Stylosanthes spp., razão pela qual, apesar das evidências contrárias, não se descartou a hipótese de que a produção de enzimas pécticas pelo patógeno influencia na sua agressividade ao estilosantes. Conforme já mencionado, enzimas pécticas são preconizadas exercerem papel durante o estabelecimento de Colletotrichum spp. e no maceramento dos tecidos do hospedeiro (BAILEY et al., 1992; ҮАКОВу et al., 2001). 


\section{CONCLUSÕES}

1. Colletotrichum gloeosporioides, agente causal da antracnose em estilosantes, possui atividade pectinolítica in vitro, a qual é variável dentro da população.

2. Nos isolados do fungo, recuperados de Stylosanthes capitata, também há diferenças quanto à agressividade em diferentes genótipos de estilosantes. No entanto, nas condições analisadas, a maior atividade pectinolítica de certos isolados do fungo não resulta em maiores níveis de severidade em plântulas de S. capitata, S. macrocephala ou S. scabra.

3. A variedade de enzimas pectinolíticas produzidas por C. gloeosporioides dificulta a análise da influência dessas enzimas na infecção do hospedeiro, tornando necessários estudos adicionais, sobretudo molecular.

\section{REFERÊNCIAS}

ALMEIDA, L.C.C. DE; COÊLHO, R.S.B. Caracterização da agressividade de isolados de Colletotrichum de maracujá amarelo com marcadores bioquímico, fisiológico e molecular. Fitopatologia Brasileira, Brasília, v.32, n.4, p.318-328. 2007.

ANNIS, S.L.; GOODWIN, P.H. Recent advances in the molecular genetics of plant cell-wall degrading enzymes produced by plant pathogenic fungi. European Journal of Plant Pathology, v.103, p.1-14, 1997.

ASSIS, T.C.; MENEZES, M.; ANDRADE, D.E.G.T.; COELHO, R.S.B.; OLIVEIRA, S.M.A. Estudo comparativo de isolados de Colletotrichum gloeosporioides quanto ao efeito da nutrição de carboidratos no crescimento, esporulação e patogenicidade em frutos e três variedades de mangueira. Summa Phytopathologica, Jaguariúna, v.27, p.208-212, 2001.

BAILEY, J.A.; O' CONNELL, R.J.; PRING, R.J.; NASH, C. Infection strategies of Colletotrichum species. In: BAILEY, J.A.; JEGER, M.J. Colletotrichum: biology, pathology and control. Wallingford: CABI. 1992. p.88-120.

CHAKRABORTY, S. Expression of quantitative resistance of Colletotrichum gloeosporioides in Stylosanthes scabra at different inoculum concentrations and day-night temperature. Australian Journal of Agriculture Research, Melbourne, v.41, p.89-100, 1990.

CHAKRABORTY, S.; CAMERON, D.F.; IRWIN, J.A.G.; EDYE, L.A. A quantitatively expressed resistance to anthracnose (Colletotrichum gloeosporioides) in Stylosanthes scabra. Plant Pathology, Oxford, v.37, p.529-537, 1988.

CHAKRABORTY, S.; FERNANDES, C.D.; CHARCHAR, M.J.D'A.; THOMAS, M. Pathogenic variation in Colletotrichum gloeosporioides infecting Stylosanthes spp. in a center of diversity in Brazil. Phytopathology, St. Paul, v.92, p.553-562, 2002.
CHAKRABORTY, S.; PERROTT, R.; CHARCHAR, M.J.D'A.; FERNANDES, C.D.; KELEMU, S. Biodiversity, epidemiology and virulence of Colletotrichum gloeosporioides. II. Genetic and pathogenic diversity in Colletotrichum gloeosporioides isolates from eight species of Stylosanthes scabra. Tropical Grasslands, Brisbane,v.31, p.387-393, 1997.

CHARCHAR, M.J.D'A.; ANJOS, J.R.N. DOS; GOMES, A.C.; AKIMOTO, A.K.; KARIA, C.T. Avaliação de acessos de Stylosanthes spp. em relação à antracnose, em condições de campo, no Distrito Federal, Brasil. Planaltina: Embrapa Cerrados, 2002. 14 p. (Boletim de Pesquisa e Desenvolvimento)

CRUZ, C.D. Programa Genes: Aplicativo computacional em Genética e Estatística. Viçosa: UFV, 2001. 648p.

DAVIS, R.D.; BOLAND, R.M.; HOWITT, C.J. The developing relationship between Stylosanthes and anthracnose after 14 years in a north Queensland. 2. Diversity in the pathogen population. Australian Journal of Experimental Agriculture, Melbourne, v.34, p.621-626, 1994.

DICKMAN, M.B.; PATIL, S.S. Cutinase deficient mutants of Colletotrichum gloeosporioides are non-pathogenic to papaya fruit. Physiological and Molecular Plant Pathology, London, v.28, p.235-242, 1986.

FERNANDES, C.D. Resistência de progênies de Stylosanthes capitata e $S$. macrocephala à antracnose causada por Colletotrichum gloeosporioides. 90p. 2003. Tese (Doutorado em Proteção de Plantas) - Faculdade de Ciências Agronômicas, Universidade Estadual Paulista "Júlio de Mesquita Filho", Botucatu.

GROF, B.; FERNANDES, C.D.; FERNANDES, A.T.F. A novel technique to produce polygenic resistance to anthracnose in Stylosanthes capitata. Proceeding. In: INTERNATIONAL GRASSLAND CONGRESS, 19., 2001, Piracicaba, Proceedings... Piracicaba: FEALQ, 2001. p.525-526.

HANKIN, L.; ANAGNOSTAKIS, S.L. The use of solid media for detection of enzyme production by fungi. Mycologia, Bronx, v.67, p.597-607, 1975.

LIMA FILHO, R.M.; OLIVEIRA, S.M.A.; MENEZES, M. Caracterização enzimática e patogenicidade cruzada de Colletotrichum spp. associados a doenças de pós-colheita. Fitopatologia Brasileira, Brasília, v.28, p.620-625, 2003.

MACCHERONI JÚNIOR, W.; ARAÚJO, W.L.; AZEVEDO, J.L. Ambient $\mathrm{pH}$-regulated enzyme secretion in endophytic and pathogenic isolates of the fungal genus Colletotrichum. Scientia Agricola, Piracicaba, v.61, p.298-302, 2004.

MANNERS, J.M.;HE, C. Recent advances in studies of anthracnose of Stylosanthes. IV. Molecular approaches to studies of Colletotrichum gloeosporioides causing anthracnose of Stylosanthes in Australia. Tropical Grasslands, Brisbane,v.31, p.435-444, 1997.

MARCHI, C.E.; BORGES. M. DE F.; MIZUBUTI, E.S.G. Atividades amilolítica e pectinolítica de Alternaria solani e a relação com a agressividade em tomateiro. Summa Phytopathologica, Jaguariúna, v.32, p.345-352, 2006. 
MILES, J.W.; LASCANO, C.E. Status of Stylosanthes development in other countries. I. Stylosanthes development and utilisation in South America. Tropical Grasslands, Brisbane, v.31, p.454-459, 1997.

PASCHOLATI, S. Fitopatógenos: arsenal enzimático. In: BERGAMIN FILHO, A.; KIMATI, H.; AMORIN, L. Manual de Fitopatologia: princípios e conceitos. São Paulo: Ceres, 1995. v.1, p. 343-364.

SAS INSTITUTE (Cary, United States). SAS ${ }^{\circledR}$ User's Guide: Statistics. Cary, 2002.

SHIH, J.; WEI, Y; GOODWIN, P.H. A comparison of the pectate lyase genes, pel-1 and pel-2, of Colletotrichum gloeosporioides $\mathrm{f}$. sp. malvae and the relationship between their expression in culture and during necrotrophic infection. Gene, Amsterdam, v.243, p.139-150, 2000.

WEI, Y.; SHIH, J.; LI, J.; GOODWIN, P.H. Two pectin lyase, pnl1 and pnl-2, from Colletotrichum gloeosporioides f. sp. malvae differ in a cellulose-binding domain and in their expression during infection of Malva pusilla. Microbiology, New York, v.148, p.2149-2157, 2002.

YAKOBY, N.; BENO-MOUALEM, D.; KEEN, N.T.; DINOOR, A.; PINES, O.; PRUSKY, D. Colletotrichum gloeosporioides pelB is an important virulence factor in avocado fruit-fungus interaction. Molecular Plant-Microbe Interactions, St. Paul, v.14, p.988-995, 2001. 